\title{
Sudden unexplained death in infancy and hyperimmunization
}

\author{
G. E. D. URQUHART, R. W. LOGAN, AND M. M. IZATT \\ From the Viral Epidemiology Unit, University of Glasgow, Ruchill Hospital, and the Department of \\ Pathological Biochemistry, Yorkhill Children's and Maternity Hospitals, Glasgow, and Glasgow and West \\ of Scotland Blood Transfusion Service, Law Hospital, Carluke, Lanarkshire
}

SYNOPSIS Serum immunoglobulin concentrations, predominantly IgM, were raised in $72 \%$ of $3 \dot{9}$ sudden infant death cases, consistent with a state of prolonged or repeated antigenic stimulation.

Anti-antibody was found in cases of sudden death significantly more frequently than in ill but living control infants. It is suggested that anti-antibody might participate in fatal anaphylaxis in such cases.

The aetiology of sudden, unexplained and unexpected death in infancy is unknown but the characteristic postmortem appearances of thoracic petechiae, organ congestion, and alveolar round cell infiltration, and the suddenness of death suggest that anaphylaxis might participate in this syndrome.

In 1965, Peeler, Kadull, and Cluff suggested that repeated antigenic stimulation might have adverse consequences in man and demonstrated abnormal laboratory tests in a proportion of hyperimmunized adults, including antiglobulin antibodies. It seemed possible that infants who experienced repeated or prolonged antigenic stimulation might develop antiglobulın antibodies and these could participate in a fatal anaphylactic reaction.

\section{Methods}

Between April 1967 and May 1969 sera were collected from 39 cases of sudden death, eight explained infant death cases, and 21 ill but living infants admitted to an infectious diseases unit from whom blood samples were submitted for viral serology.

\section{IMMUNOGLOBULIN ESTIMATIONS}

Quantitative determinations of serum immunoglobulins IgA, IgG, and IgM were performed on all sera using a single radial diffusion technique (Mancini, Vaerman, Carbonara, and Heremans, 1963; Mancini, Carbonara, and Heremans, 1965). Hoechst immunoplates, calibrated by standards obtained from Behringwerke were used. For ultimate reference, an ampoule containing $83.99 \mathrm{mg}$ of the Received for publication 24 February 1971.
WHO international standard 67/97 was reconstitutect in $1 \mathrm{ml}$ distilled water and the immunoglobulino content was determined as for the test sera. By the technique utilized, the ampoule was found to containg IgA, $1.6 \mathrm{mg}$, IgG $8.2 \mathrm{mg}$, and IgM $1.0 \mathrm{mg}$.

Sera from 96 apparently normal infants were collected independently (R.W.L.) and the immuno@ globulin contents were ascertained in an attempt tō define $95 \%$ confidence limits for normal subjects. In this group there were 26 cord blood samples frong normal infants born within two weeks of expected delivery dates. The other specimens included somes obtained on a random basis during a survey to detect the frequency of latent rickets in apparentls healthy subjects. The remaining samples were frong infants receiving routine physical examination, none of whom was known to have experienced recenB infection, allergy, or immunization. The results sबె obtained were examined with respect to theig distributions before applying the method of Hoffmann (1963) to determine the ranges shown in Figure 1을 The IgA and IgM values were used directly since these approximated to normal distributions buP those for IgG concentrations were treated logarith $\tilde{D}_{0}$ mically before plotting on probability paper. The limits of normality obtained are, however, shown as lines on linear graph paper and were used wheb assigning the test results to the appropriate cate gories: reduced, normal, or increased.

\section{ANTIGLOBULIN ANTIBODY DETECTION}

The serum of each infant was incubated (v/v) with appropriately sensitized RBCs in tubes at roong temperature for two hours. Cell sediments were 
transferred to slides and the results read microscopically. To avoid bias, the sequence in which sera from cases of unexplained sudden death and control sera were tested was selected arbitrarily and read without prior knowledge of this sequence. A negative control test of infant's serum and unsensitized RBCs was included.

An antiglobulin agglutinator was distinguished by its agglutination of group O Rh-D (+) RBCs only after these had been sensitized with $\gamma$-globulin of an 'incomplete' (IgG type) anti-Rh serum. Three lots of sensitized RBCs were prepared, each carrying a different $\gamma$-globulin coat: (1) $\mathrm{Gm}(\mathrm{a}+\mathrm{x}-),(2) \mathrm{Gm}$ $(a+x+)$, and $(3) \mathrm{Gm}(b+)$. In practice, 2 volumes of anti-Rh serum were incubated at $37^{\circ} \mathrm{C}$ for 90 minutes with 1 volume of a $50 \%$ suspension in normal saline of washed group $\mathrm{O}$ Rd-D (+) (CcDE) RBCs. The sensitized cells were washed four times in saline, and a $2 \%$ suspension in saline was used in the tests.

\section{SPECIFICITY TESTING}

Specificity tests were carried out on all sera reacting to a titre of $1 / 2$ or greater; those sera which reacted only undiluted were too weak for further examination. Agglutinators were classified as non-inhibitable if they could not be inhibited by the addition $(v / v)$ of any of a panel of normal sera of known $\mathrm{Gm}$ types; the specificity of inhibitable sera was determined where possible using the same panel.
IMMUNOGLOBULIN CLASS

Sera reacting to a titre of $1 / 2$ or greater (of which sufficient remained), were treated $(v / v)$ for two hours at $37^{\circ} \mathrm{C}$ with $0.2 \mathrm{M}$ mercaptoethanol (ME) to destroy any IgM class antibody. The serum/ME mixtures were then dialysed against normal saline for 24 hours at $4^{\circ} \mathrm{C}$ and tested for residual agglutinating ability.

\section{Results}

All infants studied were aged 6 months or less and the male-female ratio was highest in cases of sudden unexplained death $(4 \cdot 6 / 1)$ and lowest $(1 / 1)$ in the living control group. The diagnoses of explained death cases and control infants are shown in Table $I$.

\begin{tabular}{lll}
\hline Diagnosis & Living Controls & Explained Death Cases \\
\hline $\begin{array}{l}\text { Lower respiratory tract } \\
\text { infection }\end{array}$ & 10 & 1 \\
$\begin{array}{l}\text { Upper respiratory tract } \\
\text { infection }\end{array}$ & 2 & 0 \\
Rashes & 6 & 0 \\
'Gastroenteritis' & 1 & $5(4)^{2}$ \\
Miscellaneous & $2^{2}$ & $2^{2}$ \\
Total & 21 & 8 \\
\hline
\end{tabular}

Table I Diagnoses of control and explained death cases

1(4) = number 'sudden'

= aseptic meningitis, congenital heart disease

$\checkmark=$ renal infarction, septicaemia
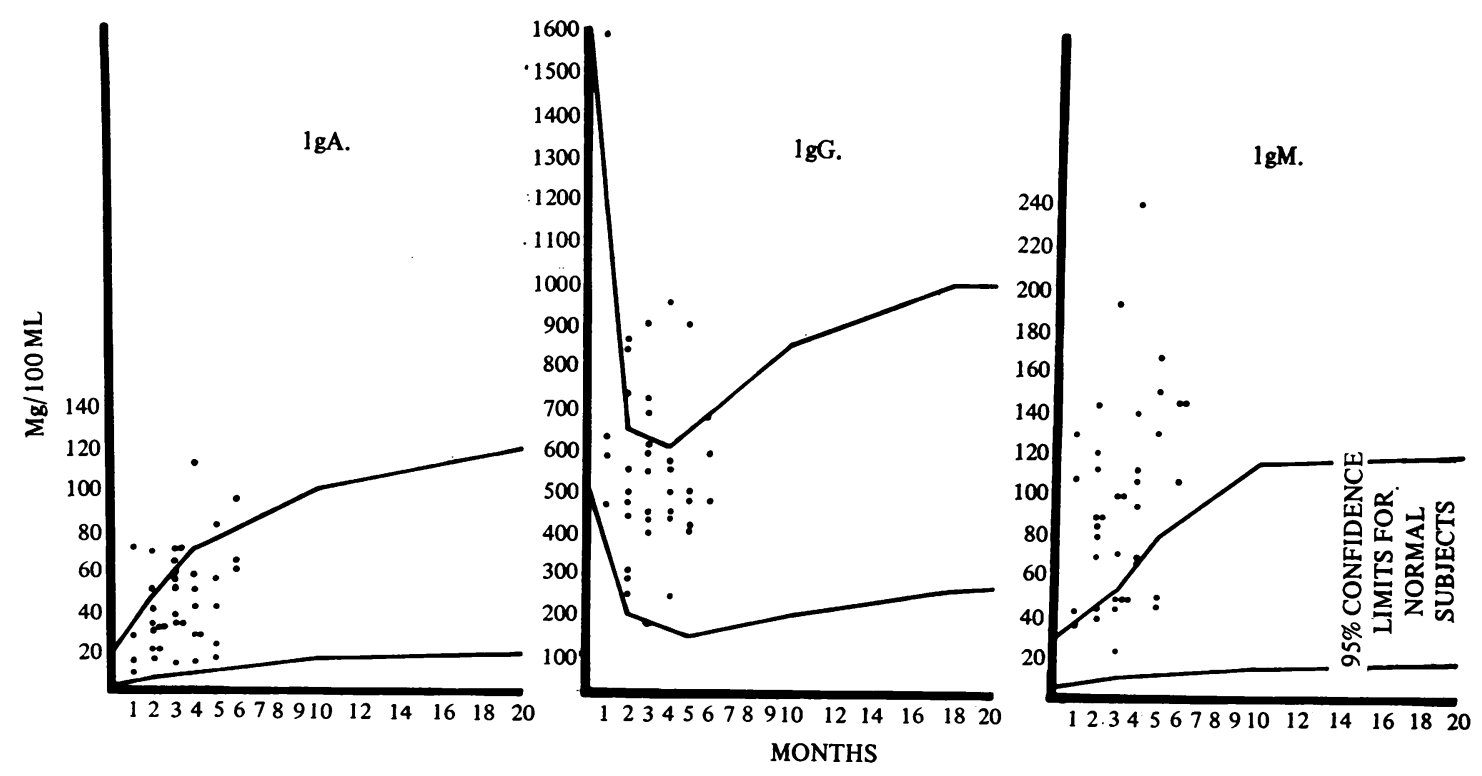

Fig. 1 Immunoglobulin estimations of 39 sudden deaths. 
IMMUNOGLOBULIN ESTIMATIONS

Figure 1 shows that in $18 \%, 21 \%$, and $67 \%$ of cases of sudden, unexplained death, serum levels of IgA, IgG, and IgM respectively were higher than levels for the 96 normal infants. In 28 cases (72\%) one or more levels were elevated and no low levels were encountered. There was no significant difference in serum immunoglobulin levels between the unexplained deaths, the eight explained deaths, and the 21 ill living infants chosen to act as controls for antiglobulin antibody tests.

\section{ANTIGLOBULIN ANTIBODIES}

Antiglobulin antibodies were detected in $56 \%$ of cases of unexplained sudden death, $50 \%$ of explained deaths, and $5 \%$ of living control cases (Table II and Fig. 2). The difference between the death cases and living controls is highly significant $\left(\chi^{2}=13 \cdot 29\right.$,
G. E. D. Urquhart, R. W. Logan, and M. M. Izato

$\mathbf{P}=<0.001$ ). Sera with antiglobulin antibodios could be subdivided into three groups according t $\overrightarrow{\mathrm{g}}$ their agglutinating activity (Tzble III):

\section{Unclassified and 'weak'}

Those sera with agglutinating activity only detectab at $1 / 1$ which were too weak to test further.

\section{Non-inhibitable}

These resembled anti-antibody (Milgrom, Dubisk and Wozniczko, 1956). There was a significants difference between death cases and living controf infants $\left(\chi^{2}=6.49, P=0.02-0.01\right)$.

\section{Specific}

There was no significant difference between the thregs groups of cases.

The maximum titres of positive sera were low

\begin{tabular}{|c|c|c|c|c|c|c|c|c|}
\hline \multirow[t]{2}{*}{ Category } & \multirow[t]{2}{*}{ No. Tested } & \multirow[t]{2}{*}{ No. Positive $(\%)$} & \multicolumn{6}{|c|}{ Titres } \\
\hline & & & 1 & 2 & 4 & 8 & 16 & 32 \\
\hline $\begin{array}{l}\text { Sudden, unexplained, unexpected death } \\
\text { Explained death } \\
\text { Living control }\end{array}$ & $\begin{array}{l}39 \\
8 \\
21\end{array}$ & $\begin{array}{l}22(56) \\
4(50) \\
1 \quad(5)\end{array}$ & $\begin{array}{l}5 \\
1 \\
1\end{array}$ & $\begin{array}{l}13^{2} \\
2 \\
0\end{array}$ & $\begin{array}{l}2 \\
1^{2} \\
0\end{array}$ & $\begin{array}{l}1^{2} \\
0 \\
0\end{array}$ & $\begin{array}{l}\mathbf{0} \\
\mathbf{0} \\
\mathbf{0}\end{array}$ & $\begin{array}{l}1^{2} \\
0 \\
0\end{array}$ \\
\hline
\end{tabular}

Table II Titres of antiglobulin antibodies ${ }^{1}$

${ }^{1}$ Reciprocal of maximum titres with the three types of sensitized RBCs

${ }^{2}$ Represents one serum with specific anti-Gm activity

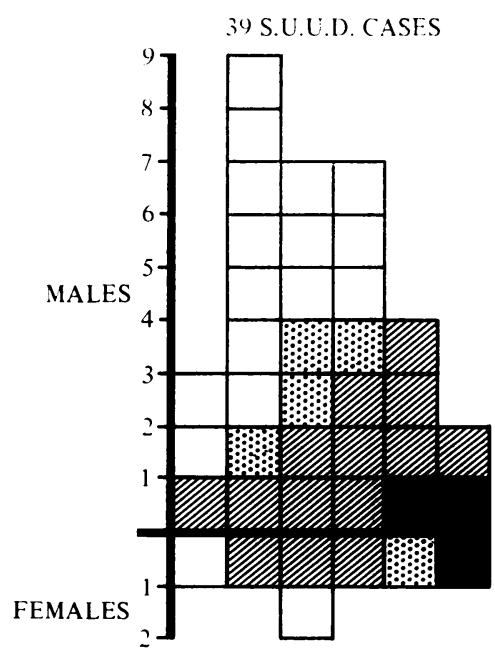

Fig. 2. Antiglobulin 'antibodies'.

\section{LIVING CONTROL INFANTS}
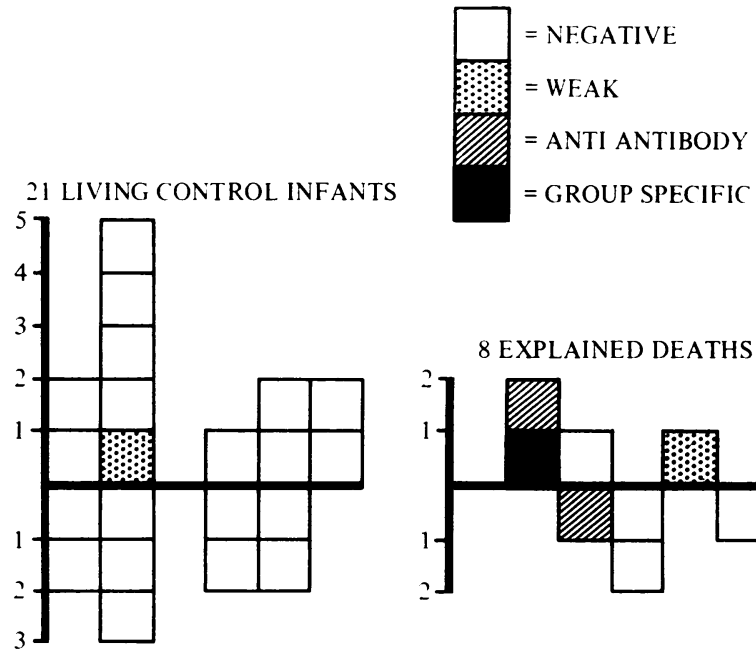

\section{EXPLAINED DEATHS}

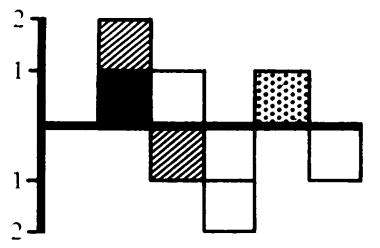

123456 


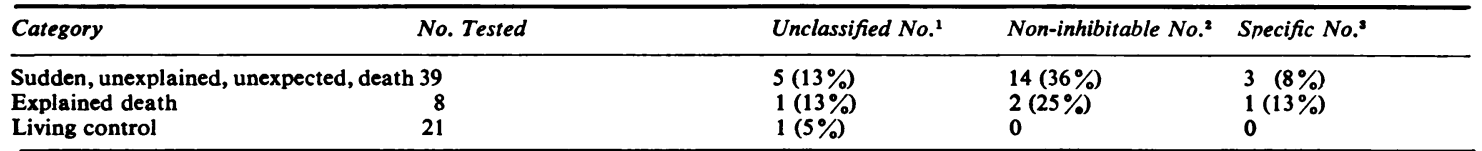

Table III Specificity of antiglobulin antibodies

'Positive at $1 / 1$ only, too weak to test further

antiantibody like

'Two anti-Gm ( $\alpha)$, two undetermined

(Table II) and $50 \%$ and $75 \%$ of the positive sera in sudden, unexplained, and explained death groups gave positive reactions with all three types of $\mathrm{Gm}$ sensitized cells. In one case with specific antibody, a 2-month-male who died from septicaemia, there was a transfusion history; maternal-foetal incompatability may have been responsible for the remaining three cases with specific anti-Gm antibody (Steinberg and Wilson, 1963).

Mercaptoethanol treatment abolished activity from 11 of 14 sera from cases of unexplained and the one explained death case serum which was ME treated, indicating that activity was associated mainly with the IgM immunoglobulin and hence of infant origin. Agglutinating activity resistant to this treatment could have been of infant or maternal origin.

The two explained deaths with anti-antibodies (Table III) died of 'gastroenteritis'; one was a sudden death and one was not sudden.

Latex tests were carried out on all sera and two were positive; one case of sudden, unexplained death with anti-antibody and one death from renal infarction without anti-antibody.

There was no significant correlation between raised immunoglobulin levels and the presence of antiglobulin antibodies.

\section{Discussion}

The significant finding of antiglobulin antibody in over $50 \%$ of 39 sudden death cases and half of eight explained deaths compared with $5 \%$ of 21 control infants was due to the presence of low levels of anti-antibody. These were mainly macroglobulins and although there was no significant association with class specific hyperglobulinaemia, the high levels of predominantly IgM were consistent with a state of prolonged or repeated antigenic stimulation.

Anti-antibodies are found significantly in rheumatoid arthritis (Lightfoot and Christian, 1969) and may be produced in animals by prolonged antigenic stimulation with bacterial antigens
(Abbruzo and Christian, 1961) but there is no proof of a role in immediate anaphylaxis.

The role of anti-antibodies in infant death cases is difficult to evaluate but it is possible that they may be produced in some antigenically hyperstimulated infants weeks or months after a microbial infection and cause fatal anaphylaxis. They might also be the result of an autoimmune process as yet undefined or merely a non-specific indicator of immunological activation.

Microbial isolation studies have shown that no single pathogen can be isolated consistently from sudden death cases (Valdes-Dapena, 1967). It is possible that a common immunological mechanism leading to death in these infants may be initiated by different antigens and operate at a time when the original antigens are no longer identifiable. Further studies around this hypothesis are essential.

We would like to thank Professor N. R. Grist and Dr J. Wallace for advice and encouragement, the pathologists involved for permission to use their material, and Miss R. Dalton for statistical help. This study was supported by M.R.C. grant G967/ $102 / C$.

\section{References}

Abbruzo, J. L., and Christian, C. L. (1961). The induction of a rheumatoid factor-like substance in rabbits. J. exp. Med., 114, 791-806.

Hoffmann, R. G. (1963). Statistics in the practice of medicine. J. Amer. med. Ass., 185, 864-873.

Lightfoot, R. W., Jr., and Christian, C. L. (1969). Rheumatoid arthritis. In Text Book of Immunopathology, vol. 2, edited by $P$. A. Miescher and H. J. Muller-Eherhard, chap. 60, pp. 733-744. Grune and Stratton, New York.

Mancini, G., Carbonara, A. O., and Heremans, J. F. (1965). Immunochemical quantitation of antigens by single radial immunodiffusion. Immunochemistry, 2, 235-254.

Mancini, G., Vaerman, J. P., Carbonara, A. O., and Heremans, J. F. (1963). Prnides binl. Fuids., 11. 370.

Milgrom, F., Dubiski, S., and Wozniczko, G. (1956). Human sera with 'Anti-antibody'. Vox. Sang. (Basel), 1, 172-183.

Peeler, R. N., Kadull, P. J., and Cluff, L. E. (1965). Intensive immunisation of man. Evaluation of possible adverse consequences. Ann. intern. Med., 63, 44-57.

Valdes-Dapena, M. A. (1967). Sudden and unexpected death in infancy: A review of the world literature 1954-66. Pediatrics. 39, $123-138$. 